Statistical Publishing Society, 1940.) As in the first session a year before, there were sections dealing with theoretical statistics, agricultural statistics, and economic statistics, but an anthropological section has been added. The medical and public health section has disappeared, which is rather surprising, in view of the recent creation of the new post of medical statistician to the Government of India and a separate post for vital statistics at the All-India Institute of Hygiene and Public Health. The annual review by the general secretary, Prof. P. C. Mahalanobis, recalled the long association of the Punjab with statistical work. The study of the connexion between snowfall in the Punjab hills and the monsoon in North India formed the basis of Sir Gilbert Walker's work on weather correlations and his statistical method for long-range forecasting of the monsoon. This led to the concept of world weather; for example, the monsoon in India is controlled by weather conditions six months earlier in Java, Africa, or South America. It was also in the Punjab that pioneer work was done by Mr. Jacob on the influence of rainfall on the yield of wheat. Statistics has played an important part in the Punjab irrigation projects. In the year under review, extensive researches have been carried out in the field and laboratory for the improvement of the jute forecast, a problem of the greatest economic importance for India. The Statistical Institute has actively helped the Government of Bengal in an elaborate crop-cutting experiment for estimating the out-turn of rice. A report has been prepared on certain anti-mosquitr experiments undertaken by the Bengal Public Health Department for the control of malaria. A diet survey on a random sample basis has been started in Calcutta. Work has also been carried' out on varioús topics in theoretical 'statistics.

\section{Education in India}

THE "Progress of Education in India, 1932-1937" by John Sargent (Government of India Press, Simla, 5s.) is a paper book of $\mathbf{2 8 5}$ pages, well supplied with statistics and diagrams. The report deals with the period before Mr. Sargent became educational commissioner, and we share his feeling that the years which elapse while publication is delayed should be reduced to a minimum. The material is, indeed, vast, but surely the reports of various provinces can be secured and summarized within a year of their receipt. The period has been one of special difficulty, due to financial stress, which did not justify the optimism of the previous report. Several provinces speak strongly about the cramping of education, but retrenchment introduced on economic grounds is being gradually relaxed. Depression has produced a consensus of opinion that the present system is not practical enough in view of the needs of later life-a point in which the United States takes the lead. Secondary education in India needs particular attention.

The Central Advisory Board of Education, abolished in 1923, was revived in 1935 and has received the comments of two experts from England. It was found to be nzeded when control was handed over to the provinces, and there is enough evidence of that in this report. The Bureau of Education at headquarters was also abolished and revived. The decrease in the number of schools is largely to be attributed to wise measures of consolidation. We note, however, that in five provinces privately managed schools made the cost per pupil lower than in others. But in the whole of British India "the percentage of pupils attending all types of schools to the total population is 5-2 only". This is clearly not enough. Local autonomy has its defects as well as its advantages. Action is taken on grounds other than educational. Party strife and personal reasons have intervened, and the power that membership of a committee gives is noted as used unsatisfactorily in the Central Provinces. Inspectors are not pleased. This is a deep-rooted evil, and it will take some time to create a proper and general sense of responsibility among Indian managers of education.

\section{Announcements}

By an Order of the Committee of Privy Council, the Right Hon. James Gray Stuart, M.P., has been appointed a member of the Medical Research Council in the vacancy caused by the resignation of Mr. R. K. Law, M.P. By another Order, made after consultation with the Medical Research Council and with the President of the Royal Society, Sir W. Wilson Jameson, dean of the London School of Hygiene and Tropical Medicine, has been appointed to be a member of the Council in succession to Prof. Matthew J. Stewart, who retires in rotation on September 30.

Ir is announced in Science that Prof. Carl Neuberg, formerly professor in the University of Berlin, for twelve years director of the Kaiser Wilhelm Institute for Biochemistry until his retirement with the title emeritus in 1937, has been appointed research professor of chemistry in the Washington Square College of Arts and Scienees of New York University. He will take up the work in September, following his arrival in the United States from Palestine, where he has been teaching at the University of Jerusalem.

THE Borden award of a medal and a thousand dollars for research in nutrition was recently made to Dr. Henry C. Sherman, Mitchill professor of chemistry, Columbia University, New York, for his researches on enzymes, vitamins and the mineral elements in nutrition.

Messrs. W. AND J. George LTD., proprietors of F. E. Becker and Co., have recently issued a new 96 -page price list of laboratory chemicals, analytical reagents, stains and solutions. A feature which will commend itself at once is the setting out in the body of the list of the maximum limits of impurity to which the analytical reagents conform; and each bottle of 'Nivoc Analytical Reagent' now bears a guarantee to this effect. 